THE SHORT STORIES of OSCAR WILDE 



\title{
THE SHORT STORIES of OSCAR WILDE
} AN ANNOTATED SELECTION

\author{
EDITED BY \\ NICHOLAS FRANKEL
}

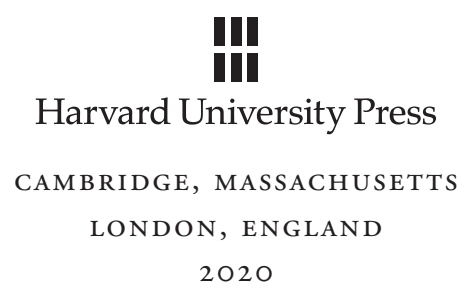


Copyright $(92020$ by the President and Fellows of Harvard College ALL RIGHTS RESERVED

Printed in the United States of America

First printing

9780674250376 (EPUB)

9780674250383 (MOBI)

9780674250390 (PDF)

Jacket design by Gabriele Wilson

Jacket illustration (C) Yuko Shimizo

The Library of Congress has cataloged the printed edition as follows:

Names: Wilde, Oscar, 1854-1900, author. | Frankel, Nicholas, 1962- editor.

Title: The short stories of Oscar Wilde : an annotated selection / Oscar Wilde ; edited by Nicholas Frankel.

Description: Cambridge, Massachusetts : Harvard University Press, 2020. |

Includes bibliographical references.

Identifiers: LCCN 20200I8204 | ISBN 9780674248670 (cloth)

Classification: LCC PR5812 .F73 2020 | DDC 823/.8—dc23

LC record available at https://lccn.loc.gov/2020018204 
For my amazing sons,

Max, Theo, and Oliver

"The aim of perfection is youth" 
